\title{
The Accumulation and Release of $\mathrm{Cd}$ and $\mathrm{Pb}$ from Edible Mushrooms and Their Biomass
}

\author{
Bożena Muszyńska ${ }^{1 *}$, Jacek Rojowski², Magdalena Lazarz ${ }^{2}$, Katarzyna Kała ${ }^{1}$, \\ Konrad Dobosz ${ }^{1}$, Włodzimierz Opoka ${ }^{1}$ \\ 'Department of Pharmaceutical Botany, Jagiellonian University Medical College, \\ Medyczna 9, 30-688 Kraków, Poland \\ ${ }^{2}$ Department of Inorganic and Analytical Chemistry, Jagiellonian University Medical College, \\ Medyczna 9, 30-688, Kraków, Poland
}

Received: 23 April 2017

Accepted: 15 June 2017

\begin{abstract}
The aim of this study was to determine the contents of cadmium and lead ions in edible mushrooms collected from the natural environment. Then the degree of heavy metals released from their fruiting bodies into artificial digestive juices was determined. The experiment involved seven species of edible mushrooms. The study also involved in vitro cultures of Imleria badia enriched with cadmium and lead, in order to determine the relationship of increased metal content in the culture medium and the degree of their accumulation in the resulting biomass. This was shown in conditions simulating the human gastrointestinal tract, after extracting from mushroom material into artificial digestive juices, and was found that the contents of cadmium and lead are well below the acceptable limits for human consumption. A small percentage of these metals released into artificial digestive juices from the in vitro cultures cultivated on media with cadmium and lead ions indicate that both metals are highly accumulated in mushrooms. It was shown that both elements are released more efficiently in the environment of gastric juice, where $23.6 \%$ and $21.5 \%$ of the total contents in the examined mushrooms were found to be cadmium and lead, respectively. Based on the obtained results, we can conclude that the examined species of mushrooms collected from their natural environment are not a threat to human health due to the presence of the examined heavy metals.
\end{abstract}

Keywords: edible mushrooms, in vitro cultures, cadmium, lead, artificial digestive juices

\section{Introduction}

Mushrooms are characterized by their much greater ability to accumulate elements compared to green plants. Thus, in some cases they can be harmful to humans [1].

*e-mail: muchon@poczta.fm
There are many external factors affecting heavy metals accumulation in mushrooms, such as the concentration of elements in the soil, $\mathrm{pH}$ of soil, amount of organic substances, and contaminants from the environment [2]. The internal factors of mushroom species are related to its structure, chemical composition, and fruiting body development, as well as accumulation ability in different morphological parts of the fruiting body [3]. The ability to accumulate heavy metals by the fruiting bodies 
of mushrooms can be regarded in two ways: using their predisposition for accumulation, they can be employed as bioindicators of environmental pollution to assess the contamination of heavy metals in soil. More significant from the consumer point of view is the evaluation of their heavy metals content for human health protection [4]. Due to the harmful action of heavy metals, it is important to properly assess their concentration and adequately monitor it to eliminate the dangers to human health [5].

Cadmium can enter the human organism mainly by inhalation, and also from food. It primarily accumulates in liver and kidneys, and to a lower extent in bones. Although it is a toxic element for humans, acute poisoning of the metal is rare, but chronic poisoning caused by the progressive collection of small amounts of cadmium by long-term exposure (e.g., from food) is more common [6]. This metal is the most dangerous for kidneys, because they are the largest site of its accumulation during human life. Chemical compounds of cadmium show teratogenic and carcinogenic activity, and disruption of liver functions, the reproductive system, and bones [5-6].

Lead is toxic to many human organs. Pathway of this element by which it passes into the organism includes the digestive tract - drinking contaminated water and eating contaminated food, inhalation, and transdermal pathway - mainly for alkyl lead connections. After absorption it gets into the circulatory system, from which it is distributed to various tissues and organs [7-8].

Because mushrooms are characterized by their good capacity to collect and accumulate metals (including heavy ones), acceptable concentrations of content in the fruiting bodies of edible species have been established. The current binding regulation of the Commission of European Communities on the maximum levels for certain contaminants in foodstuffs contains the limits for cadmium content in mushrooms from cultivation, which amount to $0.20 \mathrm{mg} \mathrm{kg}^{-1}$ fresh mass for cadmium, and up to $0.30 \mathrm{mg} \mathrm{kg}^{-1}$ fresh weight for lead. Because mushrooms contain about $87-90 \%$ water [9], the recalculation of the tolerable intake for dry mass gives limits from 2.3-3 $\mathrm{mg} \mathrm{kg}^{-1}$ dry weight for lead and 1.5-2 $\mathrm{mg} \mathrm{kg}^{-1}$ dry weight for cadmium. The presented data suggest that edible mushrooms usually do not constitute the potential danger of poisoning by heavy metals. However, due to the ability of these elements to accumulate in the human body, the concentration of these elements in foods, including mushrooms, should be monitored.

The aim of the study was to determine the contents of cadmium and lead in selected edible mushrooms. The amount of heavy metals release from their fruiting bodies into the artificial digestive juices was also examined. The experiment involved seven species of wild mushrooms collected from their natural environment. The experiment also involved in vitro cultures of I. badia on the media enriched with cadmium and lead at the concentration of $5 \cdot 10^{-5} \mathrm{~mol} \mathrm{~L}^{-1}$, in order to determine the relationship of increased metals content in the culture medium and the degree of their accumulation in the resulting biomass. Quantitative determination of metals content in the present study was performed using the method of differential pulse anodic stripping voltammetry (DP ASV), due to its low threshold of determination and good accuracy in trace analysis. The results will also allow us to determine the edible mushroom species that contain allowable limits of lead and cadmium ions based on dry weight, and to determine which part of the two metal ions is released into artificial gastric and intestinal juices. This would be used in the indirect evaluation of stability of these metal ions binding in mushrooms and consumers' exposure to heavy metals.

\section{Materials and Methods}

\section{Experimental Materials}

This study was conducted using seven species of edible mushrooms collected from their natural environment in 2014-16 in mixed or spruce forests in southern Poland: Imleria badia (Fr.) Vizzini (bay bolete), Leccinum scabrum (Bull.) Gray (birch bolete), Pleurotus ostreatus (Jacq. P. Kumm.) (oyster mushroom), Cantharellus cibarius Fr. (Chanterelle), Boletus edulis Bull. (king bolete), Agaricus campestris L. (field mushrooms), and Suillus luteus (L.) Roussel (slippery jack). Taxonomic identification of the young sporocarps was made according to online keys (mycokey.com) and authors Knudsen and Vesterholt [10]. Representative voucher specimens were deposited at the Department of Pharmaceutical Botany, Jagiellonian University Medical College, Kraków, Poland. Examination of release of the metal was carried out using the same mushroom species. In addition, the release tests involved Imleria badia biomass from in vitro cultures cultivated on media enriched with the ions of lead(II) and cadmium(II) in the Department of Pharmaceutical Botany.

\section{Experimental Cultures}

In vitro cultures from a solid medium were used to derive the experimental cultures, which were cultivated on a modified liquid medium according to Oddoux (1957). The initial inoculum from the solid medium was $0.1 \mathrm{~g}$. The resulting biomass from the cultures on a solid medium was passaged to Erlenmeyer flasks $(500 \mathrm{~mL})$ containing liquid medium $(250 \mathrm{~mL})$. The aim of culturing on a liquid medium was to obtain the highest possible growth of biomass for further analysis. The biomass was obtained from the cultures conducted on the Oddoux medium (control); it is the same medium but supplemented with cadmium(II) or lead(II) ions at a concentration of $5 \cdot 10^{-5}$ M. Three cultures of I. badia were derived for each of all variants. After four weeks of growth, the biomass from in vitro culture was separated from the liquid medium on Büchner funnel and rinsed four times with distilled water. The resulting biomass was immediately frozen and dried by lyophilization (Freezone 4.5 lyophilizer, Labconco; temperature: $-40^{\circ} \mathrm{C}$ ). 


\section{Reagents}

The standards of lead(II) and cadmium(II) ions at a concentration of $1,000 \mathrm{mg} / \mathrm{kg}$ were obtained from OUM Łódź, and serial dilutions of the following concentrations were prepared for the study: $100 \mathrm{mg} / \mathrm{kg}, 10 \mathrm{mg} / \mathrm{kg}, 1 \mathrm{mg} /$ $\mathrm{kg}$, and $0.1 \mathrm{mg} / \mathrm{kg}$, as well as $5 \cdot 10^{-5} \mathrm{~mol} / \mathrm{L} . \mathrm{MgCl}_{2}$ were obtained from Chempur (Kraków, Poland); $\mathrm{NaCl}^{2} \mathrm{KCl}$, and $\mathrm{NaHCO}_{3}$ were from PPH Galfarm (Kraków, Poland); pepsin and bile salts were from BTL (Lódź, Poland); $\mathrm{CaCl}_{2}$ was from Pharma Zentrale GmbH (Germany); pancreatic extract, $\mathrm{HCl}, \mathrm{KCl}, \mathrm{HNO}_{3}$ concentrated, Suprapur and $\mathrm{KNO}_{3}$ were obtained from Merck (Darmstad, Germany); and citric acid, $\mathrm{ZnSO}_{4}, \mathrm{KHCO}_{3}, \mathrm{Na}_{2} \mathrm{HPO}_{4}, \mathrm{~K}_{2} \mathrm{HPO}_{4}$, and $\mathrm{NaOH}$ were from the Polish Company of Chemistry (Gliwice, Poland). Water (quadruple-distilled) with a conductivity of less than $1 \mu \mathrm{S} / \mathrm{cm}$ was obtained using an S2-97A2 distillation apparatus (ChemLand, Stargard Szczecin, Poland).

Artificial digestive juices (saliva, gastric, and intestinal juice) were prepared according to Muszyńska et al. [11-12].

\section{Apparatus}

Mineralization of lyophilized fruiting bodies of mushrooms was carried out in a Magnum II microwave mineralizer by ERTEC. Mineralization of the solutions after digestion in artificial digestive juices was carried out in a UV R-8 mineral mineralizer from Poland. A measuring station consisting of an M161 electrochemical analyzer and an M164 electrode stand (both from mtmanko, Kraków), equipped with a controlled growth mercury drop electrode (CGMDE) developed by Kowalski and modified by Baś (AGH) was used to perform voltammetric analyses. The measurement system consists of three electrodes: a working electrode (CGMDE), a reference electrode (silver chloride electrode with double electrolytic junction; inner jacket $3 \mathrm{~mol} / \mathrm{L}$ $\mathrm{KCl}$ and an outer jacket $2 \mathrm{~mol} / \mathrm{L} \mathrm{KNO}_{3}$ ), and an auxiliary electrode (platinum electrode).

The release study was conducted in a prototype Gastroel-2014 device constructed in the Department of Inorganic and Analytical Chemistry at the Faculty of Pharmacy, Jagiellonian University Medical College. This device allows for examining the release of substances into the artificial digestive juices and imitates the movements of the digestive tract, and also provides a constant temperature of $37^{\circ} \mathrm{C}$ (the apparatus is in process of being patented).

\section{Preparation of Samples for the Study of Cadmium and Lead Release}

The weighed samples $(0.5000 \mathrm{~g})$ were prepared from the fruiting bodies of mushrooms collected from their natural habitat, and Imleria badia biomass derived from in vitro cultures on media enriched with ions of lead(II) and cadmium(II), whose metal concentration was $5 \cdot 10-5 \mathrm{~mol} / \mathrm{L}$. Then the samples were crushed and transferred to Erlenmeyer flasks, to which $2 \mathrm{~mL}$ of artificial saliva and $10 \mathrm{~mL}$ of artificial gastric juice were added. The flasks were placed in a Gastroel-2014 device, and the extraction was carried out for 60 minutes. Then the contents of the flasks were filtered with a Büchner funnel using a vacuum. The residue was transferred to Erlenmeyer flasks along with $10 \mathrm{~mL}$ of intestinal juice. The digestion process was performed for 150 minutes. Then the content was filtered again.

\section{Determining Cadmium and Lead in Soil Samples}

Soil samples collected from a natural mushroom occurrence area (Rabka and Sucha Beskidzka) were taken from $5 \mathrm{~cm}$ below forest surface and dried at $75^{\circ} \mathrm{C}$ for four hours and ground in a mortar. Three portions of approximately $500 \mathrm{mg}$ of each sample were accurately weighed and mineralized in a microwave digestion unit in a Teflon bomb. Decomposition was obtained by using a mixture of two concentrated acids: $6 \mathrm{~mL}$ nitric acid and $2 \mathrm{~mL}$ of hydrofluoric acid. The mineralization process was carried over for one hour in three stages $60 / 80 / 100 \%$ power of magnetron. Samples from the bomb were transferred quantitatively to a platinum crucible and evaporated to almost dry in order to remove as much residual acid as possible. The sample was then dissolved in a $10 \mathrm{~mL}$ polypropylene volumetric flask. Cadmium and lead concentrations were determined by means of anodic stripping voltammetry.

Soil samples after microwave digestion were added $(50 \mu \mathrm{L})$ to the measurement cell and then three standard additions of $10 \mu \mathrm{L}$ at a concentration of $0.1 \mathrm{mg} / \mathrm{kg}$ for cadmium(II) and $1 \mathrm{mg} / \mathrm{kg}$ for lead(II) were also added. The concertation was determined based on voltammetric peak height.

\section{Determining Cadmium and Lead in Mushroom Samples}

The weighted samples were appropriate to the parameters of an applied mineralizer, which were 0.260 $\mathrm{g}$ on average, and were prepared from the fruiting bodies and the biomass from in vitro cultures enriched with $\mathrm{Cd}(\mathrm{II})$ and $\mathrm{Pb}(\mathrm{II})$ ions. Later, the samples were subjected to microwave mineralization, adding $4 \mathrm{~mL}$ of concentrated nitric acid(V) solution and $1 \mathrm{~mL}$ of hydrogen peroxide to the reaction vessel. The process was conducted in six cycles. The same temperature range, $295-300^{\circ} \mathrm{C}$, was set during the entire process. After mineralization, the content of the vessel was transferred to a quartz dish and evaporated to "almost dry" on a hot plate at about $220^{\circ} \mathrm{C}$. Four-times-distilled water was added to the residue to allow quantitative transfer to volumetric flasks, which were finally completed to a volume of $10 \mathrm{~mL}$.

Measurement conditions are shown in Table 1. The $200 \mu \mathrm{L}$ of sample containing mineralized fruiting bodies and three samples of the standard $(10 \mu \mathrm{L}$ each) were 
Table 1. Differential pulse parameters for anodic stripping voltammetry measurements.

\begin{tabular}{|c|c|c|}
\hline Parameter & Cadmium & Lead \\
\hline Accumulation potential $(\mathrm{mV})$ & -950 & -750 \\
\hline Accumulation time $(\mathrm{s})$ & 25 & 25 \\
\hline Start potential $(\mathrm{mV})$ & -950 & -750 \\
\hline End potential $(\mathrm{mV})$ & -700 & -450 \\
\hline Time of delay $(\mathrm{ms})$ & 20 & 20 \\
\hline Sampling time $(\mathrm{ms})$ & 20 & 20 \\
\hline Step potential $(\mathrm{mV})$ & 4 & 4 \\
\hline Pulse amplitude $(\mathrm{mV})$ & -20 & -20 \\
\hline
\end{tabular}

added to the measuring cell with $\mathrm{pH}$ neutral supporting electrolyte $\left(0.06 \mathrm{~mol} / \mathrm{L} \mathrm{KNO}_{3}\right)$ purged with argon gas. A standard of a concentration of $0.1 \mathrm{mg} / \mathrm{kg}$ was used for determining cadmium(II) ions, while the concentration of $1 \mathrm{mg} / \mathrm{kg}$ was applied for lead(II) ions. The $10 \mu \mathrm{L}$ of sample containing mineralized biomass from in vitro cultures and three additions of the standard, $10 \mu \mathrm{L}$ each, were added to the measuring cell.

\section{Determining Cadmium and Lead in Samples after Extraction}

The collected filtrate was transferred to quartz tubes and the mineralization was carried out using a UV lamp. This process is conducted by exposing the mineralized solution to UV radiation in a quartz reaction vessel in several cycles of 6-8 hours. The solutions after mineralization were transferred to quartz evaporating dishes and evaporated to "almost dry" on a hot plate at a temperature of about $200^{\circ} \mathrm{C}$. Four-times-distilled water was added to the residue in quartz evaporating dishes for a quantitative transfer to a volumetric flask, which was finally completed with water to a volume of $10 \mathrm{~mL}$.

Sample volumes of 10,50 , or $200 \mu \mathrm{L}$ of mineralized extracts of mushroom material after incubating in artificial digestive juices were used to carry out the analyses of metals content. Three standard additions of $10 \mu \mathrm{L}$ at a concentration of $0.1 \mathrm{mg} / \mathrm{kg}$ for cadmium(II) and $1 \mathrm{mg} / \mathrm{kg}$ for lead(II) were added to the cell. The

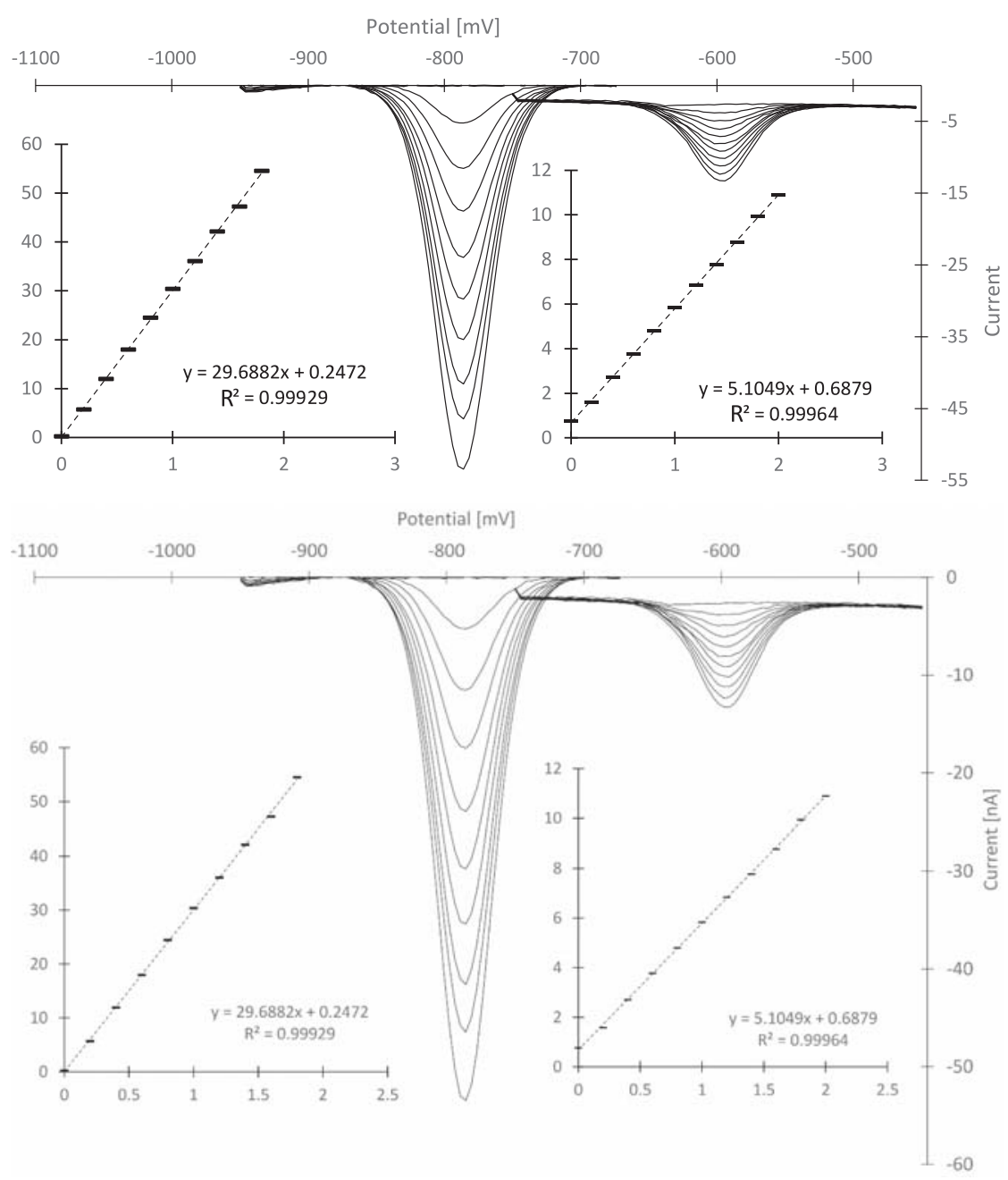

Fig. 1. Voltammetric curves recorded by differential pulse anodic stripping voltammetry for the subsequent addition of cadmium and lead ions standard at a concentration of $0.1 \mathrm{mg} \mathrm{kg}^{-1}$. 
concentration of metals was determined using the standard addition method.

Three runs of voltammetric curve were registered for each addition of the sample or standard. Three measurements were made for each sample. Development of the curves and interpretation of results was performed using EAGRAPH 6.0 software. Voltammetric measurement parameters were the same as previously applied for soil samples.

Samples of in vitro culture medium and control samples of artificial digestive juices were checked for cadmium and lead using the protocol previously applied to ready extracts.

\section{Validation of the Method}

The following characteristics were subjected to validation in this study in accordance with the guidelines of ICH Q2-R1 document [13]: linearity, precision, accuracy, sensitivity, and specificity.

Linearity was determined by adding subsequent portions of standard (separate for cadmium(II) and lead(II)) at a concentration of $0.1 \mathrm{mg} / \mathrm{kg}$ to the basic electrolyte. The measurements were registered three times after each addition of the standard - the standards were added 10 times. From the curves observed, the registered currents were found to be linearly dependent to the concentrations of cadmium, and lead as shown in Fig. 1.

After repeated $(n=7)$ determinations of cadmium(II) and lead(II) ions content in the examined samples by standard addition method, the precision of the method was calculated on the basis of relative standard deviation (RSD). The precision of the method defined by the RSD for cadmium(II) ions was $4 \%$ and for lead(II) ions it was $3 \%$.

In order to determine the accuracy of the results, the contents of cadmium(II) and lead(II) ions were determined in the certified reference material, tobacco leaves of virginia type (CTA-VTL-2). The calculated average recovery rates for the method were $90.7 \%$ for cadmium and $93.4 \%$ for lead. The detection limit for cadmium(II) was $0.0234 \mu \mathrm{g} / \mathrm{kg}$, while for lead(II) it was $0.019 \mu \mathrm{g} / \mathrm{kg}$.

The determined limit of quantification for cadmium(II) was $0.081 \mu \mathrm{g} / \mathrm{kg}$, while for lead(II) ions it was $0.063 \mu \mathrm{g} / \mathrm{kg}$. In order to determine the specificity of the applied method, Cadmium(II) and lead(II) ions were analyzed in the presence of 100 -fold excess of zinc(II) and copper(II) ions concentration, which proved that their presence did not affect the process of determination or the results of the examined metals content significantly.

\section{Data Analysis}

Statistical analysis of the data was performed using one-way ANOVA with Tukey-Kramer post hoc method of multiple comparisons. The value $p<0.05$ was accepted as the level of statistical significance.

\section{Results and Discussion}

The technique of differential pulse anodic stripping voltammetry (DP ASV), one of the most widely used analytical techniques in such analyses, was applied to evaluate the content of cadmium and lead in the fruiting bodies of the seven selected edible mushrooms and mycelium from in vitro cultures and from their extracts in artificial gastric juices. Developed mineralization conditions of lyophilized material and the applied analytical validation method allowed the efficient determination of the analyzed elements in the fruiting bodies from the wild-type mushrooms and mycelia obtained from in vitro cultures of I. badia.

The analyses of the content and release of healthpromoting substances and organic compounds from the fruiting bodies into artificial digestive juices and extracts of edible mushrooms were performed previously [11, 14] to the analysis of heavy metals under the environment of digestive juices was carried out later in this study.

Cadmium and lead are among the most frequently analyzed heavy metals due to their toxicity [15-16], but there is no information about the amount of these elements that can be absorbed into the human body. For this reason, analyses of the content of lead and cadmium ions in mushroom material after digestion in the artificial digestive juices (60 minutes for artificial gastric juice and 150 minutes for artificial intestinal juice) under conditions simulating the human intestinal tract were performed

Table 2. Mean content of cadmium and lead ions in soil samples of mushrooms collected from the natural state $\left(\mathrm{mg} \mathrm{kg}^{-1} \mathrm{DW}\right.$; Oddoux medium, saliva, gastric and intestinal juices shown, cadmium, and lead levels below the detection limit).

\begin{tabular}{|c|c|c|}
\hline $\begin{array}{c}\text { Control/examined } \\
\text { species }\end{array}$ & $\begin{array}{c}\text { Mean content } \\
\pm \mathrm{SD} \\
\mathrm{Cd}\left(\mathrm{mg} \mathrm{kg}^{-1} \mathrm{DW}\right)\end{array}$ & $\begin{array}{c}\text { Mean content } \\
\pm \mathrm{SD} \\
\mathrm{Pb}\left(\mathrm{mg} \mathrm{kg}^{-1} \mathrm{DW}\right)\end{array}$ \\
\hline $\begin{array}{l}\text { Soil (Sucha } \\
\text { Beskidzka) }\end{array}$ & $0.19 \pm 0.02$ & $3.51 \pm 0.73$ \\
\hline Soil (Rabka) & $0.30 \pm 0.02$ & $8.60 \pm 0.87$ \\
\hline \multicolumn{3}{|l|}{ Examined species } \\
\hline Imleria badia & $0.11 \pm 0.03^{\mathrm{a}}$ & $0.05 \pm 0.01^{\mathrm{a}}$ \\
\hline Leccinum scabrum & $0.49 \pm 0.10^{\mathrm{a}, \mathrm{b}}$ & $1.02 \pm 0.01^{\mathrm{a}, \mathrm{b}}$ \\
\hline Pleurotus ostreatus & $0.20 \pm 0.0^{\mathrm{b}, \mathrm{c}}$ & $0.66 \pm 0.12^{\mathrm{a}, \mathrm{c}}$ \\
\hline Cantharellus cibarius & $0.25 \pm 0.09^{\mathrm{b}, \mathrm{d}}$ & $1.01 \pm 0.19^{\mathrm{a}, \mathrm{d}}$ \\
\hline Boletus edulis & $1.03 \pm 0.07^{\text {a,b.c.d.e }}$ & - \\
\hline Agaricus campestris & $0.26 \pm 0.03^{\mathrm{b}, \mathrm{e}}$ & $1.48 \pm 0.10^{\mathrm{a}, \mathrm{c.f}}$ \\
\hline Suillus luteus & $0.21 \pm 0.02^{\mathrm{b}, \mathrm{e}}$ & $2.21 \pm 0.48^{\mathrm{b}, \mathrm{c}, \mathrm{d} . \mathrm{f}}$ \\
\hline
\end{tabular}

Data are presented as the mean $\pm \mathrm{SD}$ (standard deviation); $\mathrm{n}=3$ repetitions. Tukey-Kramer test was used to reveal the differences between paired groups of elements in rows, the same letters (a,b,c,d,e, and f) are marked for which the content differences are statistically significant

(for $p$ values $<0.05$; GraphPad InStat). 
in the present study for the first time. The study was conducted using Gastroel-2014. The contents of cadmium and lead in mushrooms harvested from the natural state are shown in Table 2.

The average content of cadmium ions in the examined mushrooms is from 0.1 to $1.0 \mathrm{mg} \mathrm{kg}^{-1}$ dry weight (DW). All presented results are below the standard for this element, which is $2 \mathrm{mg} \mathrm{kg}^{-1}$ dry matter. The highest content of cadmium ions was determined in Boletus edulis at about $1 \mathrm{mg} \mathrm{kg}^{-1} \mathrm{DW}$ and in L. scabrum at about $0.5 \mathrm{mg} \mathrm{kg}^{-1} \mathrm{DW}$. The content of cadmium was about $0.2 \mathrm{mg} \mathrm{kg}^{-1} \mathrm{DW}$ in other mushroom species, such as Pleurotus ostreatus, Cantharellus cibarius, Agaricus campestris, and Suillus luteus. The lowest content of cadmium was noted in I. badia, where its amount was $0.1 \mathrm{mg} \mathrm{kg}^{-1} \mathrm{DW}$. The highest amount of lead, $2.2 \mathrm{mg} \mathrm{kg}^{-1}$ DW, was determined in S. luteus, and lower values of $1.5 \mathrm{mg} \mathrm{kg}^{-1} \mathrm{DW}$ were determined in $A$. campestris and L. scabrum. In C. cibarius it was about $1 \mathrm{mg} \mathrm{kg}^{-1} \mathrm{DW}$, whereas the lowest content of lead ions was found in $I$. badia at $0.05 \mathrm{mg} \mathrm{kg}^{-1} \mathrm{DW}$. No presence of lead ions was observed in the examined samples of $B$. edulis.

The content of metals in mushrooms was found to be highly dependent on their habitat. Many research teams from around the world have studied the content of heavy metals in different species of edible mushrooms, e.g., Falandysz et al. [17] conducted research in Poland, Garcia et al. in Spain [3, 18], Xin-Hua et al. and Zhu in China [5, 19], Cocchi et al. in Italy [4], and Svoboda et al. in a former silver mine in the Czech Republic [20]. A summary of the results of metals examinations (including heavy metals) in uncontaminated areas are presented in the review paper by KALAČ [16]. The contents of cadmium and lead from the fruiting bodies of mushrooms were similar to those determined in the present study, and were in the range of 0.5-5 and 1-10 $\mathrm{mg} \mathrm{kg}^{-1} \mathrm{DW}$, respectively [16].

As can be seen in Table 2, the habitat of mushrooms under study turned out to be relatively clean as normally soils contain higher amounts of heavy metals, exceeding $750 \mathrm{mg} \mathrm{kg}^{-1}$ for lead in polluted areas. Under normal circumstances lead and cadmium amounts in soils in Europe do not exceed $60 \mathrm{mg} \mathrm{kg}{ }^{-1}$ and $1 \mathrm{mg} \mathrm{kg}^{-1}$, respectively [21].

The results obtained in the current paper prove that after the introduction of mushrooms (collected from their natural environment) into the artificial digestive juices (gastric and intestinal juices) in conditions simulating the human digestive tract, the contents of cadmium ions from the extract is below $2 \mathrm{mg} \mathrm{kg}^{-1} \mathrm{DW}$, and lead ions below $3 \mathrm{mg} \mathrm{kg}^{-1} \mathrm{DW}$. We observed that both elements are more effectively released into the environment of gastric juices, and the amount of examined metal ions released in extracts are found to be below the detection limit of the applied method, which confirms that the fruiting bodies of edible mushrooms pose little risk as a source of contamination of lead and cadmium ions.

In view of the results, it was decided to carry out an analysis of the release of these ions in vitro from $I$. badia biomass on Oddoux medium enriched with $\mathrm{Pb}$ and
Cd. These conditions were used to examine the manner in which the increased content of $\mathrm{Pb}$ and $\mathrm{Cd}$ can affect the degree of their accumulation and their release into the artificial digestive juices from the biomass (Tables 3-4), which represents a higher amount of cadmium and lead than fruiting bodies harvested from a natural state. Biomass from Oddoux medium, which contained $5 \cdot 10^{-5} \mathrm{~mol} \mathrm{~L}^{-1}$, showed similar content of cadmium and lead to mushrooms collected from polluted arrears described by Kalač (2010). This material was chosen for further examinations involving checking the release of toxic metals from fruiting bodies of mushrooms.

Lyophilized samples of $I$. badia biomass enriched with cadmium and lead ions were digested using artificial digestive juices. Comparison of the results of cadmium content in particular mushroom species are presented in Table 2. Based on the determined contents of cadmium and lead, an antagonism between them at the stage of accumulation can be observed. The average concentrations of heavy metals in I. badia growing in laboratory conditions on media with cadmium and lead at a concentration of $5 \cdot 10^{-5} \mathrm{~mol} \mathrm{~L}^{-1}$ are $12.3 \mathrm{mg} \mathrm{kg}^{-1} \mathrm{DW}$ for cadmium and $36.7 \mathrm{mg} \mathrm{kg}^{-1} \mathrm{DW}$ for lead. This indicates that I. badia shows a substantially greater potential for the accumulation of lead than cadmium. Gastric juice contained $2.9 \mathrm{mg} \mathrm{kg}^{-1} \mathrm{DW}$ of cadmium and nearly 8 $\mathrm{mg} \mathrm{kg}^{-1} \mathrm{DW}$ of lead, which represents $23.6 \%$ and $21.5 \%$

Table 3. Mean content of cadmium and lead ions in biomass from in vitro culture of Imleria badia on Oddoux medium with the addition of heavy metals ( $\left.\mathrm{mg} \mathrm{kg}^{-1} \mathrm{DW}\right)$.

\begin{tabular}{|c|c|}
\hline Examined sample & $\begin{array}{c}\text { Mean content } \pm \text { SD } \\
\left(\mathrm{mg} \mathrm{kg}^{-1} \mathrm{DW}\right)\end{array}$ \\
\hline $\begin{array}{c}\text { With the addition of cadmium(II) } \\
\text { ions } 5 \cdot 10^{-5} \mathrm{M}\end{array}$ & $12.32 \pm 1.163$ \\
\hline $\begin{array}{c}\text { With the addition of lead(II) ions } \\
5 \cdot 10^{-5} \mathrm{M}\end{array}$ & $36.77 \pm 1.198$ \\
\hline
\end{tabular}

Table 4. Mean content of cadmium and lead ions in biomass from in vitro culture of Imleria badia on Oddoux medium with the addition of heavy metals $\left(\mathrm{mg} \mathrm{kg}^{-1} \mathrm{DW}\right)$ after incubating in artificial digestive juices.

\begin{tabular}{|c|c|}
\hline Examined sample & $\begin{array}{l}\text { Mean content } \pm \text { SD } \\
\quad\left(\mathrm{mg} \mathrm{kg}^{-1} \mathrm{DW}\right)\end{array}$ \\
\hline \multicolumn{2}{|l|}{ Gastric juice } \\
\hline $\begin{array}{l}\text { With the addition of cadmium(II) ions } \\
\qquad 5 \cdot 10^{-5} \mathrm{M}\end{array}$ & $2.88 \pm 0.35$ \\
\hline $\begin{array}{l}\text { With the addition of lead(II) ions } \\
\qquad 5 \cdot 10^{-5} \mathrm{M}\end{array}$ & $7.95 \pm 0.84$ \\
\hline \multicolumn{2}{|l|}{ Intestinal juice } \\
\hline $\begin{array}{l}\text { With the addition of cadmium(II) ions } \\
\qquad 5 \cdot 10^{-5} \mathrm{M}\end{array}$ & $0.02 \pm 0.01$ \\
\hline $\begin{array}{l}\text { With the addition of lead(II) ions } \\
\qquad 5 \cdot 10^{-5} \mathrm{M}\end{array}$ & $0.58 \pm 0.02$ \\
\hline
\end{tabular}




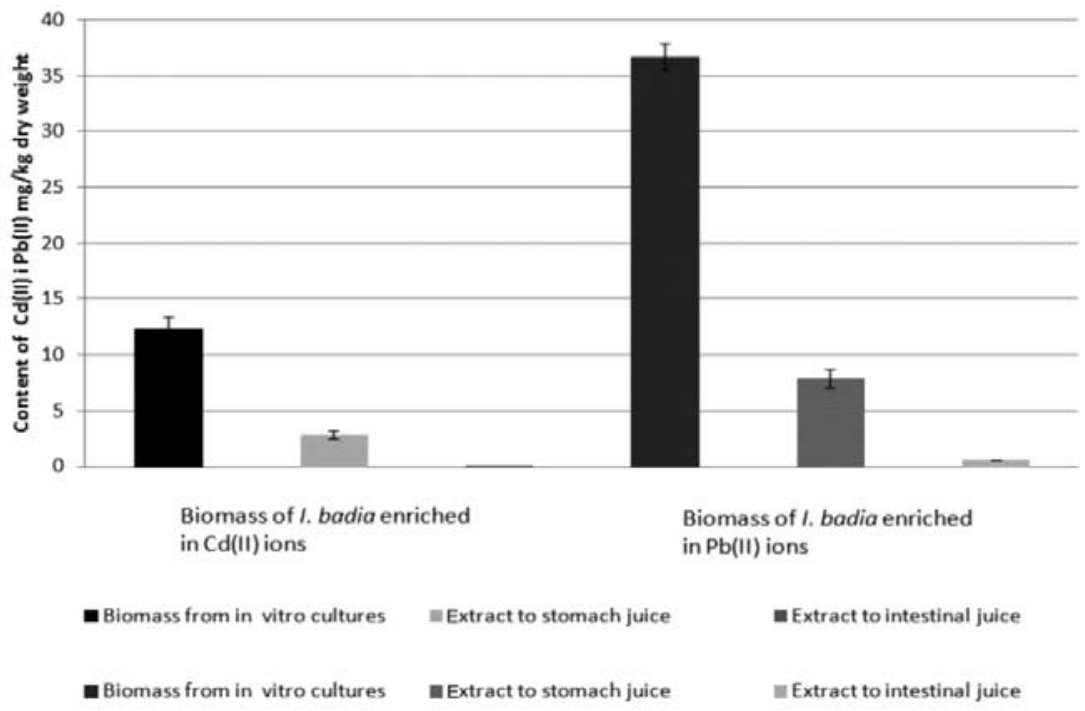

Fig. 2. Comparison of the content of cadmium and lead ions in the biomass from in vitro cultures of Imleria badia obtained from Oddoux medium enriched with heavy metals ions, before and after incubation in artificial digestive juices.

of the total amount in the sample derived from in vitro culture, respectively. In turn, intestinal juice contained $0.04 \mathrm{mg} \mathrm{kg}^{-1} \mathrm{DW}$ of cadmium and $0.58 \mathrm{mg} \mathrm{kg}^{-1} \mathrm{DW}$ of lead, which only constitutes $0.33 \%$ of the initial amount of cadmium and $1.58 \%$ of the initial amount of lead in the examined mycelium. A summary of the content of examined metals from I. badia biomass before and after incubation in artificial gastric juices is presented in Fig. 2.

The results determined for the metals content after incubation in artificial digestive juices show that both elements are much better released from the samples in an environment simulating the conditions prevailing in the stomach than in the prevailing environment in the intestine.

\section{Conclusions}

Based on the obtained results, it can be concluded that the examined species of mushrooms collected from their natural habitats are not a threat to human health. The results concerning the content of cadmium and lead are well below the acceptable standards for human consumption. This is confirmed by the small percentage of these metals released into artificial digestive juices from the in vitro cultures on media with added cadmium and lead. The fact that both metals are highly accumulated in mushrooms and to a small extent are released into artificial digestive juices proves their standards for consumption, and also emphasizes their role as a soil remediation factor. However, the question as to what part of metals released into the digestive juices is absorbed has to be solved by further research. For this purpose, the further stage of the research will involve determining the released elements and the amount that was absorbed by the way of passive and/or an active transport of these metals.

\section{Acknowledgements}

This project was supported by Jagiellonian University Medical College grant: K/ZDS/005619.

\section{References}

1. NAGAJYOTI P.C., LEE K.D., SREEKANTH T.V.M. Heavy metals, occurrence and toxicity for plants: a review. Environ. Chem. Lett. 8 (3), 199, 2010.

2. MAJCHROWSKA-SAFARYAN A., KALEMBASA D., PAKUŁA K. Impact of a spent mushroom substrate, Agaricus bisporus on chromium and copper speciation in the humus horizon. J. Elem., 19 (2), 459, 2014.

3. LANE E.A., CANTY M.J., MORE S.J. Cadmium exposure and consequence for the health and productivity of farmed ruminants. Res. Vet. Sci. 101, 132, 2015.

4. HUANG Y., HE C., SHEN C., GUO J., MUBEEN S., YUAN J., YANG Z. Toxicity of cadmium and its health risks from leafy vegetable consumption. Food Funct. 8, 1373, 2017.

5. ZHU F., QU L., FAN W., QIAO M., HAO H., WANG X. Assessment of heavy metals in some wild edible mushrooms collected from Yunnan Province, China. Environ. Monit. Assess., 179 (1-4), 191, 2011.

6. BERNHOFT R.A. Cadmium Toxicity and Treatment. Sci. World J. Article ID 394652, 2013.

7. DAMODARAN D., VIDYA SHETT K., RAJ MOHAN B. Uptake of certain heavy metals from contaminated soil by mushroom-Galerina vittiformis. Ecotoxicol Environ Saf. 104, 414, 2014.

8. ANGELI J.K., CRUZ PEREIRA C.A., FARIA T.O., STEFANON I., PADILHA A.S., VASSALLO D.V. Cadmium exposure induces vascular injury due to endothelial oxidative stress: the role of local angiotensin II and COX-2. Free Radical Bio. Med. 65, 838, 2013.

9. MUSZYŃSKA B., SUŁKOWSKA-ZIAJA K., WOŁKOWSKA M., EKIERT H. Chemical, pharmacological, and biological characterization of the culinary-medicinal honey mushroom, Armillaria mellea 
(Vahl) P. Kumm. (Agaricomycetideae). A Review. Int. J Med. Mushrooms. 13 (2), 167, 2011.

10. KNUDSEN H., VESTERHOLT J. Funga Nordica: agaricoid, boletoid and cyphelloid genera. Copenhagen: Nordsvamp. 1, 519, 2008.

11. MUSZYŃSKA B., KAŁA K., SUŁKOWSKA-ZIAJA K., KRAKOWSKA A., OPOKA W. Agaricus bisporus and its in vitro culture as a source of indole compounds released into artificial digestive juices. Food Chem. 199, 509, 2016.

12. ZAJĄC M., MUSZYŃSKA B., KAŁA K., SIKORA A., OPOKA W. Popular species of edible mushrooms as a good source of zinc released to artificial digestive juices. J Physiol Pharmacol. 66, 763, 2015.

13. BOQUE R., MAROTO A., RIU J., RIUS F.X .Validation of Analytical Methods. Grasas Aceites. 53 (1), 128, 2002.

14. MUSZYŃSKA B., SUŁKOWSKA-ZIAJA K., ŁOJEWSKI M., OPOKA W., ZAJĄC M., ROJOWSKI, J. Edible mushrooms In prophylaxis and treatment of human diseases. Med. Inter. Rev. 4, 170, 2013.

15. PENG Q., CHEN W., WU L., BAI L. The Uptake, Accumulation, and Toxic Effects of Cadmium in Barnyardgrass (Echinochloa crus-galli). Pol. J. Environ. Stud. 26 (2), 779, 2017.
16. KALAČ P. Trace element contents in European species of wild growing edible mushrooms: A review for the period 2000-2009. Food Chem. 122 (1), 2, 2010.

17. FALANDYSZ J., DREWNOWSKA M. Macro and trace elements in common chanterelle (Cantharellus cibarius) mushroom from the European background areas in Poland: composition, accumulation, dietary exposure and data review for species. J Environ Sci Health B, 50 (5), 374, 2015.

18. GARCIA M.A., ALONSO J., MELGAR M.J. Lead in edible mushrooms, levels and bioaccumulation factors. J Hazard Mater. 167, 777, 2009.

19. XIN-HUA C., HONG-BO Z., GUAN-ZHOU Q. Analysis of several heavy metals in Wild edible Mushrooms from regions of China. Bull Envinron Contam Toxicol. 83 (2), 280, 2009.

20. SVOBODA L., HAVLICKOVA B., KALAČ P. Contents of cadmium, mercury and lead in edible mushrooms growing in a historical silver-mining area. Food Chem., 96 (4), 580, 2006.

21. TÓTH G., HERMANN T., DA SILVA M.R., MONTANARELLA L. Heavy metals in agricultural soils of the European Union with implications for food safety, Environ. Int. 88, 299, 2016 